\title{
Cyclic Polyhydroxy Ketones. I. Oxidation Products of Hexahydroxybenzene (Benzenehexol)
}

\author{
Alexander J. Fatiadi, Horace S. Isbell, and William F. Sager*
}

(December 11, 1962)

\begin{abstract}
Reliable procedures are given for the preparation and purification of hexahydroxybenzene (benzenehexol), tetrahydroxy- $p$-benzoquinone, rhodizonic acid, triquinoyl (cyclohexanehexone), croconic acid, and leuconic acid (cyclopentanepentone). Certain derivatives and color tests, as well as infrared and ultraviolet spectra, are reported for their identification.
\end{abstract}

\section{Introduction}

On oxidation, cyclohexanehexols (inositols) yield keto derivatives which, by successive enolization and elimination reactions, can be transformed to polyhydroxybenzenes [1-5]. ${ }^{1}$ In progressing from cyclohexane derivatives through cyclic olefinic intermediates to aromatic compounds, reactions and materials are encountered which are eminently suited for the study of reaction mechanisms and basic concepts of theoretical organic chemistry [6].

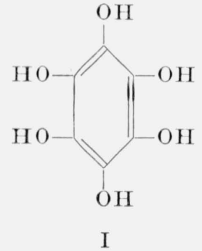

Hexahydroxybenzene (Benzenehexol)



III

Rhodizonic acid



Croconic acid

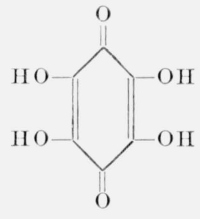

II

Tetrahydroxy- $p$-benzoquinone

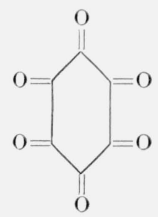

IV

'Triquinoyl (Cyclohexanehexone)

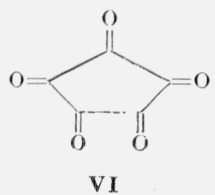

Leuconic acid (Cyclopentanepentone)
* The George Washington University, Washington, D. C.

1 Figures in brackets indicate the literature references at the end of this paper.
Hexahydroxybenzene (benzenehexol, I) can be prepared from inositols (cyclohexanehexols) and from tetrahydroxy- $p$-benzoquinone (II, obtained by selfcondensation of glyoxal in alkaline solution). Oxidation of I yields II, which is further oxidized to rhodizonic acid (III), and this is oxidized to triquinoyl (cyclohexanehexone, IV). Tetrahydroxyp-benzoquinone and rhodizonic acid are not only interesting in their own right, but also serve as intermediates in the preparation of croconic acid (V), a dihydroxy triketone having a five-carbon ring. Oxidation of croconic acid vields leuconic acid (VI). Because these compounds, needed as model substrates in a study of antioxidant and oxygen-carrier properties, were not available in a suitable state of purity, the methods reported in the experimental part were developed for their synthesis and purification.

\section{Hexahydroxybenzene (Benzenehexol, I) [7]}

\subsection{Discussion}

Hexahydroxybenzene (I), the enolic form of the trihydroxytriketocyclohexanes, can be prepared by the self-condensation of potassium carbonyl followed by hydrolysis $[8,9]$, by nitration of di-O-acetylhydroquinone followed by reduction and hydrolysis [10], by oxidation of myo-inositol followed by enolization [11], and by reduction of tetrahydroxy- $p$ benzoquinone (II) by means of stannous chloride [12].

\subsection{Preparation of Hexahydroxybenzene [13] ${ }^{2}$}

Stannous chloride dihydrate (100 g, 0.44 mole) is added in one portion to a boiling, mechanically stirred solution of $10 \mathrm{~g}$ ( 0.058 mole) of tetrahydroxy$p$-benzoquinone (II) in $200 \mathrm{ml}$ of $2.5-N$ hydrochloric acid. In a few minutes, the red color of II disappears and long, needle-like crystals of hexa-

${ }^{2}$ This procedure was developed in 1959 by one of us (A.J.F.), under the direction of Dr. William F. Sager at George Washington University [13], and was briefly described by Fieser and Fieser [14]. 
hydroxybenzene (I) begin to form. Concentrated hydrochloric acid $(250 \mathrm{ml}$; specific gravity 1.08) is added, and the stirred suspension is heated to boiling, mixed with $600 \mathrm{ml}$ of concentrated hydrochloric acid, cooled in ice, and filtered with suction on a fritted-glass filter. As much solvent as possible is removed by suction, without exposure to air, by covering the filter with an inverted funnel and introducing nitrogen, and by using a polyethylene dam to remove the final traces of the solvent.

For purification, the crude product is dissolved in $450 \mathrm{ml}$ of hot $2.5-N$ hydrochloric acid containing $3 \mathrm{~g}$ of stannous chloride dihydrate. Decolorizing carbon is added, the hot suspension is filtered, the insoluble matter is washed with $75 \mathrm{ml}$ of hot water, and the combined filtrate and washings are mixed with 1 liter of concentrated hydrochloric acid and cooled in ice. The resulting crystals are collected on a fritted-glass filter, in an atmosphere of nitrogen, washed with $100 \mathrm{ml}$ of a cold, 1:1 mixture of ethanol and concentrated hydrochloric acid, and dried over sodium hydroxide in a vacuum desiccator to give 7 to $8 \mathrm{~g}$ (about $75 \%$ ) of colorless crystals which do not melt ${ }^{3}$ when placed on a hot plate at $310^{\circ} \mathrm{C}$. Infrared and ultraviolet absorpcion spectra are recorded on pages 158 and 160 .

Hexahydroxybenzene can also be recrystallized from 2-methoxyethanol by the addition of benzene; the crystals are separated, washed with acetone, and dried in a vacuum desiccator. The yield is about the same as in the previous method.

Characteristic derivatives of hexahydroxybenzene are the hexaacetate, $\operatorname{mp} 203$ to $205^{\circ} \mathrm{C}[10,15]$, the hexabenzoate, mp 323 to $325{ }^{\circ} \mathrm{C}$ [9], and the hexamethyl ether, $\mathrm{mp} 81{ }^{\circ} \mathrm{C}$ [16].

The following convenient color tests may be used for identification of hexahydroxybenzene:

(a) (Developed in this laboratory.) A solution of ferric chloride in 1:1 aqueous methanol is slowly added dropwise to a stirred, aqueous solution of hexahydroxybenzene under a stream of nitrogen. As addition of the ferric chloride proceeds, the color of the solution passes successively through the following characteristic series, representing oxidation steps: magenta or cherry red (II) ; green (III) ; and, finally, a stable, deep blue (presumably a mixture of III and IV). When the solution is cooled in ice for several hours, colorless crystals of the octahydrate of IV gradually separate.

(b) [9] One $\mathrm{ml}$ of a concentrated, aqueous solution of barium chloride is mixed with $0.5 \mathrm{ml}$ of a dilute, aqueous solution of ferric chloride containing one or two drops of acetic acid (or of dilute hydrochloric acid). To the mixed solution are added one or two drops of an aqueous solution of hexahydroxybenzene. A bright-red precipitate of barium rhodizonate results.

\footnotetext{
${ }^{3}$ Unless the product is thoroughly washed, it may contain traces of tin salts. The presence of tin can be determined by dissolving a sample in nitric acid, evaporating the solution, and igniting the residue. When the recrystallization is conducted properly, this test does not provide any appreciable final residue Use of stannous chloride in the recrystallization prevents the formation of undesired oxidation products.
}

(c) [9] One $\mathrm{ml}$ of a dilute, aqueous solution of hexahydroxybenzene is mixed with $1 \mathrm{ml}$ of a saturated, aqueous solution of magnesium nitrate, and a few drops of dilute ammonia are added. A carminered precipitate results.

\section{Tetrahydroxy-p-benzoquinone (II) [17]}

\subsection{Discussion}

The preparation of tetrahydroxy-p-benzoquinone is based on the self-condensation of glyoxal in the presence of sodium sulfite, air, and a base. The procedure was originated by Homolka [15], and has been studied and modified by subsequent workers [18, 19, 20]. Presumably, hexahydroxybenzene is formed initially; this is oxidized to tetrahydroxy- $p$-benzoquinone, and this, in turn, to rhodizonic acid. As shown by Fatiadi and Sager [13], when sodium bicarbonate is used as a buffer, the disodium salt of tetrahydroxy-p-benzoquinone is formed in a yield of 8 to 11 percent. When the reaction mixture is highly alkaline, substantial quantities of disodium rhodizonate and disodium croconate are formed, in addition to the disodium salt of tetrahydroxy-p-benzoquinone.

\subsection{Preparation of the Disodium Salt of Tetra- hydroxy-p-benzoquinone [13]}

A solution of $400 \mathrm{~g}$ (3.17 moles) of anhydrous sodium sulfite and $150 \mathrm{~g}$ (1.79 moles) of sodium bicarbonate in 3 liters of water is placed in a 5-liter, threenecked flask fitted with a thermometer, an air inlet tube (1-cm diam), and a tube connected to a water aspirator. The solution is heated to 40 to $45^{\circ} \mathrm{C}$, and $600 \mathrm{~g}$ of a 30-percent, aqueous solution of glyoxal (3.1 moles) is added. A brisk stream of air is drawn through the solution for $1 \mathrm{hr}$ without heating, after which the mixture is gradually heated to $90{ }^{\circ} \mathrm{C}$. Aeration is then stopped, and the mixture is heated to incipient boiling and cooled to room temperature. The resulting, crystalline disodium salt of II is removed by filtration, washed successively with $50 \mathrm{ml}$ of cold, 50-percent, aqueous methanol and $50 \mathrm{ml}$ of methanol, and dried in a vacuum desiccator. The yield ( 22 to $24 \mathrm{~g}$ ) corresponds to about 10 percent of the theoretical, based on the glyoxal used. 'The product can be used without purification for the preparation of tetrahydroxybenzene, rhodizonic acid, or croconic acid. It is sensitive to oxidation by air and, if stored in a loosely stoppered bottle, is completely oxidized to disodium rhodizonate in several months. Tetrahydroxy-p-benzoquinone is, however, relatively stable in air.

\subsection{Preparation of Tetrahydroxy-p-benzoquinone}

The crude disodium salt of II $(20 \mathrm{~g})$ is dissolved in $220 \mathrm{ml}$ of $2.5-N$ hydrochloric acid by heating. On cooling, the solution yields glistening, black crystals of tetrahydroxy- $p$-benzoquinone which are collected by filtration, washed with ice water, and dried in a vacuum desiccator; wt, 12 to $15 \mathrm{~g}$. 'The product is recrystallized from warm, $2-N$ hydro- 
chloric acid to give lustrous, dark crystals [8]; alternatively, it may be recrystallized from acetone by the addition of petroleum ether to give small, dark crystals. Spectrograms are given on pages 158 and 160 .

\section{Rhodizonic Acid (III) [21]}

\subsection{Discussion}

Heretofore, rhodizonic acid (III), the oxidation product of II, has been prepared by oxidation of myo-inositol with nitric acid [11], by reduction of IV with sulfurous acid $[10,16,20]$, and by synthesis from glyoxal [15]. Described below are the preparation of ammonium rhodizonate [21] from glyoxal, and of rhodizonic acid from the disodium salt of II by oxidation in air.

\subsection{Preparation of Tetrahydroxy-p-benzoquinone and Ammonium Rhodizonate from Glyoxal}

Aqueous glyoxal (600 $\mathrm{g}$ of a 30 -percent solution) is self-condensed in the presence of sodium sulfite, oxygen, and sodium bicarbonate as described in section 3.2. After $1 \mathrm{hr}$ of aeration, $100 \mathrm{~g}$ of sodium hydroxide is added. The alkaline solution $(p \mathrm{H} \mathrm{10})$ is heated, with aeration, to incipient boiling, and cooled to room temperature. The mixture of crystalline sodium salts of II and III is filtered off and washed successively with $50 \mathrm{ml}$ of cold, $50-$ percent aqueous methanol and $50 \mathrm{ml}$ of methanol. The air-dried salts (24 to $26 \mathrm{~g}$ ) are dissolved in $200 \mathrm{ml}$ of $2.5-N$ hydrochloric acid by boiling, and the solution is immediately cooled in ice. " The resulting crystalline II ( 8 to $9 \mathrm{~g}$ ) is separated by filtration, washed with $20 \mathrm{ml}$ of ice water, and dried.

The ice-cold, dark-red filtrate is brought to $p \mathrm{H} 5.5$ to 6.5 with ammonia. The resulti g, darkblue, crystalline ammonium rhodizonate is separated by filtration, washed with $25 \mathrm{ml}$ of ice water, and air-dried; wt, 7 to $8 \mathrm{~g}$. It is recrystallized from $750 \mathrm{ml}$ of hot water.

\subsection{Preparation of Rhodizonic Acid from the Disodium Salt of II}

The disodium salt of II ( $40 \mathrm{~g})$, prepared as described in section 3.2, is placed in a large, flat-bottomed dish and heated in an oven at 170 to $180{ }^{\circ} \mathrm{C}$ for $24 \mathrm{hr}$. The residue is suspended, with mechanical stirring, in $200 \mathrm{ml}$ of warm, 2.5- $N$ hydrochloric acid, and after several minutes, $1 \mathrm{~g}$ of decolorizing carbon is added; the solution is cooled in ice and filtered through a filter paper precoated with paper pulp. The brownish-yellow solution is concentrated under diminished pressure at $35^{\circ} \mathrm{C}$ to a semicrystalline mass, and the aqueous hydrochloric acid is removed by successive addition and evaporation of three $50-\mathrm{ml}$ portions of a $1: 1$ mixture of benzene and acetone. The residue is triturated with $50 \mathrm{ml}$ of acetone, the suspension is filtered, and the insoluble product is washed with sufficient cold acetone to

${ }^{4}$ Prolonged heating causes disproportionation [22]. remove all colored impurities. The crystalline residue, consisting of sodium chloride and crude rhodizonic acid dihydrate, is air-dried and pulverized, and the powder is added to $200 \mathrm{ml}$ of dioxane preheated to $80{ }^{\circ} \mathrm{C}$. The suspension is stirred for 5 min and then filtered through a filter paper precoated with decolorizing carbon. The insoluble matter is washed with $50 \mathrm{ml}$ of warm dioxane, and the slightly colored filtrate is cooled to about $20{ }^{\circ} \mathrm{C}$. Pentane (about $150 \mathrm{ml}$ ) is added to incipient turbidity, and crystallization of rhodizonic acid dihydrate is induced by scratching the inside walls of the container with a glass rod. The mixture is cooled in ice for about $30 \mathrm{~min}$, the suspension is filtered, and the crystals are washed with $50 \mathrm{ml}$ of a cold, $1: 1$ mixture of dioxane and pentane, and air-dried; wt, 25 to $35 \mathrm{~g}$.

The crude rhodizonic acid dihydrate is recrystallized from warm dioxane by the addition of pentane and ether; by concentration of the filtrate, an additional crop is obtained. The air-dried product, which still contains dioxane, is dried for $48 \mathrm{hr}$ in a vacuum desiccator over sulfuric acid; total yield, about $21 \mathrm{~g}(60 \%)$ of colorless crystals. Measurements of infrared and ultraviolet absorption are reported on pages 158 and 160 .

The purity of the product may be determined by titration with iodine [20]; $155 \mathrm{mg}$ of rhodizonic acid dihydrate consume $14.97 \mathrm{ml}$ of $0.1-\mathrm{N} \mathrm{I}_{3}^{-}$solution; found, $15.07 \mathrm{ml}$.

If subjected to a high vacuum $(0.1 \mathrm{~mm})$ at room temperature the compound is converted into the scarlet-red crystals of anhydrous rhodizonic acid in as little as $5 \mathrm{~min}$. The same transformation can be accomplished at higher temperatures by vacuum sublimation [20]. Rhodizonic acid gives a colorless solution in 2.5- $N$ hydrochloric acid, whereas tetrahydroxy-p-benzoquinone gives a cherry-red solution.

\section{Triquinoyl (Cyclohexanehexone, IV)}

[23]

\subsection{Discussion}

In 1862, Lerch [24] obtained a product, now known as triquinoyl, by oxidation of either hexahydroxybenzene (I) or tetrahydroxy-p-benzoquinone (II) with nitric acid or chlorine. The substance has been characterized by Nietzki and coworkers [8, 10, 25], and studied by Henle [26], Bergel [27], and Eistert and coworkers $[20,22]$. The procedure described here is based on the original work of Lerch and of Nietzki. Because some workers have experienced difficulty in the preparation and purification of IV, the procedures are given in detail.

\subsection{Preparation of Triquinoyl Octahydrate}

Recrystallized tetrahydroxy- $p$-benzoquinone (10 g) is added in small increments during $5 \mathrm{~min}$ to a mechanically stirred solution of $100 \mathrm{ml}$ of concentraten nitric acid and $25 \mathrm{ml}$ of water kept at $10^{\circ} \mathrm{C}$. The reaction is continued for an additional $5 \mathrm{~min}, 25 \mathrm{ml}$ of water is added, and the mixture is cooled in ice for $15 \mathrm{~min}$. The crystalline triquinoyl octahydrate that separates is filtered off, washed successively with $20 \mathrm{ml}$ of ice water and $30 \mathrm{ml}$ of an ice-cold, 
1:1 mixture of acetone and ether, and air-dried; wt, 12 to $12.5 \mathrm{~g} ; \mathrm{mp} 96$ to $97{ }^{\circ} \mathrm{C}$.

The substance is recrystallized in the following manner: The octahydrate $(5 \mathrm{~g})$ is suspended in $50 \mathrm{ml}$ of methanol containing $3 \mathrm{ml}$ of concentrated nitric acid, and the suspension is heated to 55 to $60{ }^{\circ} \mathrm{C}$, with stirring. When dissolution is complete, about $200 \mathrm{mg}$ of decolorizing carbon is added, the suspension is filtered, and the insoluble matter is washed with $25 \mathrm{ml}$ of water. The combined filtrate and washings are evaporated under diminished pressure to about $25 \mathrm{ml}$, and the solution is cooled in ice until crystallization begins, and then gradually diluted with $20 \mathrm{ml}$ of acetone. The crystals are collected on a filter, washed successively with $10 \mathrm{ml}$ of cold 1:1 acetone-water mixture and $20 \mathrm{ml}$ of cold acetone, and air-dried; wt, $2.1 \mathrm{~g}$. By concentration of the mother liquor, additional material $(0.6 \mathrm{~g})$ is obtained. The octahydrate consists of colorless, lustrous plates or prisms, mp 99 to $100{ }^{\circ} \mathrm{C}$ (decomposition). Infrared and ultraviolet absorption spectra are recorded on pages 159 and 161 .

A characteristic color test [26] for IV involves heating the compound with a saturated, aqueous solution of barium chloride; bright-red barium rhodizonate is precipitated, following disproportionation $[8,22]$.

\section{Croconic Âcid (V) [28]}

\subsection{Discussion}

Croconic acid $(\mathrm{V})$ is one of the first enediolic acids to have been reported. Since its discovery by Gmelin [29] in 1825, it has engaged the attention of many workers [10, 30-39]. As pointed out by Hirata and coworkers [36], the anion has an unusual resonance structure. Croconic acid is formed from a variety of polyhydroxybenzene derivatives by oxidation followed by a rearrangement of the benzylic acid type. It can be efficiently prepared by oxidation of tetrahydroxy- $p$-benzoquinone or rhodizonic acid with manganese dioxide. In the process, the benzene ring is degraded, with elimination of carbon dioxide. The reaction was discovered by Nietzki [32] and has since been used by many workers. The procedure given here resembles one described by Yamada and Hirata [40], and differs from prior methods in that it starts with the crude mixture of sodium salts obtained from the condensation of glyoxal (instead of with pure sodium rhodizonate) and uses a special type [41] of active manganese dioxide as the oxidant.

\subsection{Preparation of Active Manganese Dioxide}

Commercial manganese carbonate $(500 \mathrm{~g})$ in a flat-bottomed tray or dish is heated in an oven at 295 to $310^{\circ} \mathrm{C}$ for 12 to $18 \mathrm{hr}$. After being cooled, the product is treated with sufficient aqueous nitric acid (15 to $20 \mathrm{ml}$ of concentrated acid per $100 \mathrm{ml}$ of solution) to decompose any residual carbonate and to give a strongly acid solution. After 30 to 45 min, the manganese dioxide is filtered off, thoroughly washed with water, and dried at 150 to $160{ }^{\circ} \mathrm{C}$ for 18 to $24 \mathrm{hr}$. After its recovery from reaction mixtures, active manganese dioxide can be used repeatedly if it is redried at 150 to $160{ }^{\circ} \mathrm{C}$ for 18 to $24 \mathrm{hr}$. Manganese dioxide prepared by other methods proved to be less satisfactory.

\subsection{Barium Croconate Hydrate}

To a solution of $40 \mathrm{~g}$ of sodium hydroxide in 1.2 liters of water are added, with stirring, $21 \mathrm{~g}(0.1$ mole) of crude disodium tetrahydroxy- $p$-benzoquinone (see section 3.2 ) and $55 \mathrm{~g}$ of active manganese dioxide. After $5 \mathrm{~min}$, the mixture is heated to boiling, refluxed for $45 \mathrm{~min}$, and filtered, and the manganese dioxide is washed with $800 \mathrm{ml}$ of hot water. The combined filtrate and washings are treated with about $210 \mathrm{ml}$ of concentrated hydrochloric acid in portions, giving a bright-yellow solution. To this is added a hot solution of $50 \mathrm{~g}$ of barium chloride dihydrate in $150 \mathrm{ml}$ of water, with stirring; the mixture is heated to 85 to $90{ }^{\circ} \mathrm{C}$, cooled, and kept at room temperature. The resulting, lustrous, yellow plates of barium croconate monohydrate are collected on a filter, washed successively with water and ethanol, and air-dried; wt, 22 to $23 \mathrm{~g}$.

\subsection{Conversion of Barium Croconate to Sodium Croconate}

Barium croconate $(17.5 \mathrm{~g} ; 0.06$ mole) is added in small portions, with stirring, to $150 \mathrm{ml}$ of a 10 percent aqueous solution of anhydrous sodium carbonate. The mixture is boiled for $5 \mathrm{~min}$ and filtered; the barium carbonate is washed with 30 $\mathrm{ml}$ of hot water, and the combined yellow filtrate and washings are diluted with $20 \mathrm{ml}$ of glacial acetic acid, heated to boiling, and cooled in ice. Disodium croconate trihydrate separates in long, yellow crystals, which are collected on a filter, washed with $40 \mathrm{ml}$ of ice water, and air-dried; wt, about $10 \mathrm{~g}$. A second crop (2.5 to $3.5 \mathrm{~g}$ ) is obtained by adding about $200 \mathrm{ml}$ of 95 -percent ethanol to the mother liquor and cooling the solution.

Dipotassium croconate may be prepared similarly.

\subsection{Croconic Acid Trihydrate}

Barium croconate $(55 \mathrm{~g})$ is added in small portions to $200 \mathrm{ml}$ of mechanically stirred, aqueous sulfuric acid (containing $20 \mathrm{ml}$ of concentrated acid) at 55 to $60{ }^{\circ} \mathrm{C}$; stirring is continued for 30 to $45 \mathrm{~min}$. The barium sulfate is separated by filtration, washed with $25 \mathrm{ml}$ of hot water, and discarded. The combined filtrate and washings are evaporated to dryness under diminished pressure, the residue is dissolved in a hot solution of $25 \mathrm{ml}$ of absolute ethanol and $150 \mathrm{ml}$ of dioxane, and the solution is treated with a small quantity of decolorizing carbon and filtered. The filtrate is concentrated under diminished pressure at $40{ }^{\circ} \mathrm{C}$ until crystallization begins, and the mixture is diluted with benzene to incipient turbidity and cooled. 
After several hours, the resulting crystals are separated by filtration, washed with benzene, and dried in a vacuum desiccator. By concentration of the mother liquor, additional crystals are obtained; the combined yield of croconic acid trihydrate is about $20 \mathrm{~g}$. Infrared and ultraviolet absorption spectra are recorded on pages 159 and 161 .

Anhydrous croconic acid is prepared by heating the trihydrate at $120{ }^{\circ} \mathrm{C}$ for 2 to 4 hrs; it slowly decomposes above $150{ }^{\circ} \mathrm{C}$. Croconic acid may be characterized as the dimethyl ether, mp $113{ }^{\circ} \mathrm{C}[35]$.

Small quantities of croconic acid may be prepared by passing a solution of $5 \mathrm{~g}$ of disodium croconate in $300 \mathrm{ml}$ of water through $80 \mathrm{ml}$ of a cation-exchange resin (Amberlite $120-\mathrm{H}^{+}$), concentrating the effluent under diminished pressure, and crystallizing the product from dioxane with the addition of ether, benzene, or pentane.

\subsection{Preparation of Manganese Croconate Trihydrate}

A solution of $5 \mathrm{~g}$ of croconic acid trihydrate in $50 \mathrm{ml}$ of hot water is treated, with stirring, with a hot, saturated, aqueous solution of manganous acetate until a precipitate forms. The mixture is cooled to room temperature, and the resulting greenish-yellow crystals are separated by filtration. The product is recrystallized from water by the addition of acetone; the yield is almost quantitative.

Analysis: Calculated for $\mathrm{C}_{5} \mathrm{MnO}_{5} \cdot 3 \mathrm{H}_{2} \mathrm{O}: \mathrm{C}, 24.1$; H, 2.41. Found: C, 24.0; H, 2.5.

\subsection{Analysis of Croconic Acid}

The purity of samples of croconic acid may be determined by titration with a standard solution of potassium permanganate (see eq (1)).

$$
\begin{gathered}
12 \mathrm{KMnO}_{4}+23 \mathrm{H}_{2} \mathrm{SO}_{4}+5 \mathrm{Na}_{2} \mathrm{C}_{5} \mathrm{O}_{5} \rightarrow 6 \mathrm{~K}_{2} \mathrm{SO}_{4}+ \\
12 \mathrm{MnSO}_{4}+25 \mathrm{CO}_{2}+5 \mathrm{Na}_{2} \mathrm{SO}_{4}+23 \mathrm{H}_{2} \mathrm{O} \text { (1) }
\end{gathered}
$$

A 50-mg sample of disodium croconate, previously dried at $120{ }^{\circ} \mathrm{C}$ for $1 \mathrm{hr}$, is transferred to a $250-\mathrm{ml}$ Erlenmeyer flask with 25 to $50 \mathrm{ml}$ of water. Sulfuric acid $(50 \mathrm{ml}$ of $3.6 \mathrm{~N})$ is added, and the solution is heated to $80{ }^{\circ} \mathrm{C}$ and rapidly titrated with $0.1-N$ potassium permanganate to the complete disappearance of the original yellow color. Then $5 \mathrm{ml}$ of a 5 -percent solution of zinc chloride is added, and the addition of permanganate is continued dropwise with swirling, until a faint pink color, stable for about 1 min, is produced. A 50-mg sample of disodium croconate monohydrate consumed $29.20 \mathrm{ml}$ of $0.1-N$ potassium permanganate; calculated for $\mathrm{Na}_{2} \mathrm{C}_{5} \mathrm{O}_{5} \cdot \mathrm{H}_{2} \mathrm{O}: 29.40 \mathrm{ml}$.

\section{Leuconic Acid (Cyclopentanepentone, VI) [42]}

\subsection{Discussion}

Leuconic acid was first prepared by Will [43] in
1861. Particularly noteworthy investigations were made by Nietzki [32], Homolka [44], and Eistert and coworkers [22]. The procedure given in the present paper is a modification of that of Nietzki.

\subsection{Preparation of Leuconic Acid Pentahydrate}

Purified anhydrous croconic acid $(2 \mathrm{~g})$, or an equivalent amount of the trihydrate, is added in portions, with stirring, to $20 \mathrm{ml}$ of ice-cold, concentrated nitric acid during $3 \mathrm{~min}$, and the mixture is stirred until evolution of nitrogen dioxide ceases (about $10 \mathrm{~min}$ ). Then $20 \mathrm{ml}$ of ice-cold methanol is added, and the mixture is stirred while crystallization of leuconic acid pentahydrate occurs; after $10 \mathrm{~min}$, the crystals are separated by filtration, washed with methanol, and air-dried; wt, about $2.7 \mathrm{~g}$.

For recrystallization, the compound is dissolved in the minimal quantity of water; the solution is treated with decolorizing carbon and filtered, and the filtrate is concentrated under diminished pressure at $40{ }^{\circ} \mathrm{C}$ to about $5 \mathrm{ml}$. After the addition of several drops of concentrated nitric acid, the solution, on cooling, yields colorless crystals of leuconic acid pentahydrate. Infrared and ultraviolet absorption spectra are given on pages 159 and 161 .

Crystalline leuconic acid pentahydrate may be isolated from concentrated, aqueous solution by adding a 1:1 mixture of 2-propanol and ethanol; this product is devoid of nitric acid.

The pentahydrate melts with dehydration at 115 to $118{ }^{\circ} \mathrm{C}$, followed by slow decomposition at 158 to $162{ }^{\circ} \mathrm{C}$. Leuconic acid may be characterized as the pentaoxime [32], mp $172{ }^{\circ} \mathrm{C}$. In the present study, it has been found that the oxime may conveniently be recrystallized from $N, N$-dimethylformamide.

When a saturated solution of sodium carbonate is added to an aqueous solution of leuconic acid, a pink color is produced, followed by deposition of a difficultly soluble, white precipitate of the sodium salt of mesoxalic acid [44].

\section{Spectrophotometric Measurements}

Figure 1 reports infrared spectrograms for the freshly prepared, crystalline compounds in Nujol mulls. The measurements were made with a Perkin-Elmer Infracord Model 137 (double beam) spectrophotometer equipped with a prism of sodium chloride for the $2-$ to $15-\mu$ range.

The ultraviolet absorption measurements given in figure 2 were made with a Beckman DK-2 spectrophotometer with matched, $1-\mathrm{cm}$ quartz cells and the appropriate solvent as the reference standard. In the course of time, the spectra for some of the compounds change, presumably from oxidation reactions. To minimize oxidation, freshly boiled solvents were used, but complete exclusion of oxygen was not attempted. 

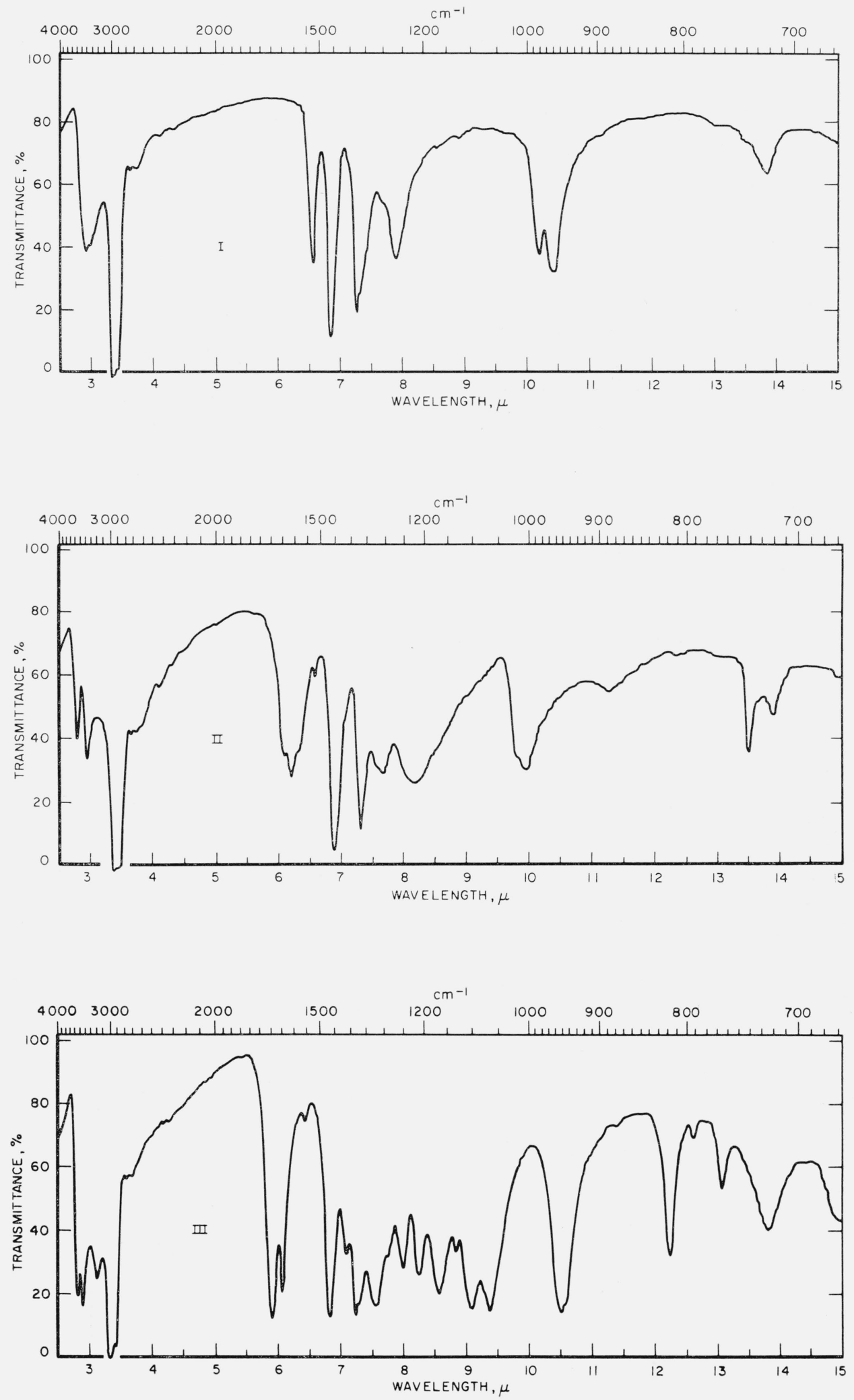

Figure 1. Infrared spectrograms of materials in Nujol mulls.

I, Hexahydroxybenzene; II, tetrahydroxyquinone; III, rhodizonic acid dihydrate. 

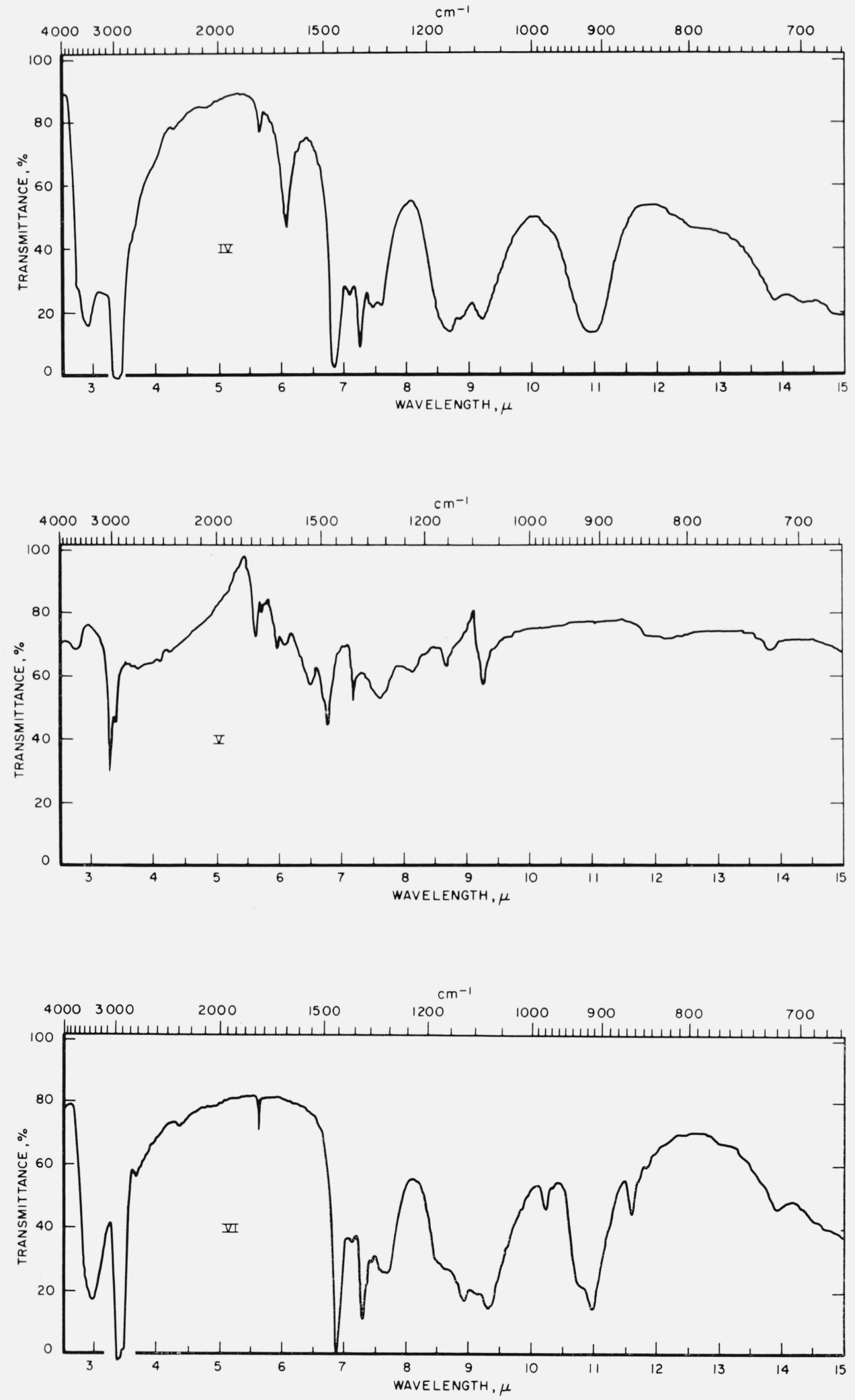

FiguRE 1. Infrared spectrograms of materials in Nujol mulls-Continued IV, Triquinoyl octahydrate; V, croconic acid trihydrate; VI, leuconic acid pentahydrate. 

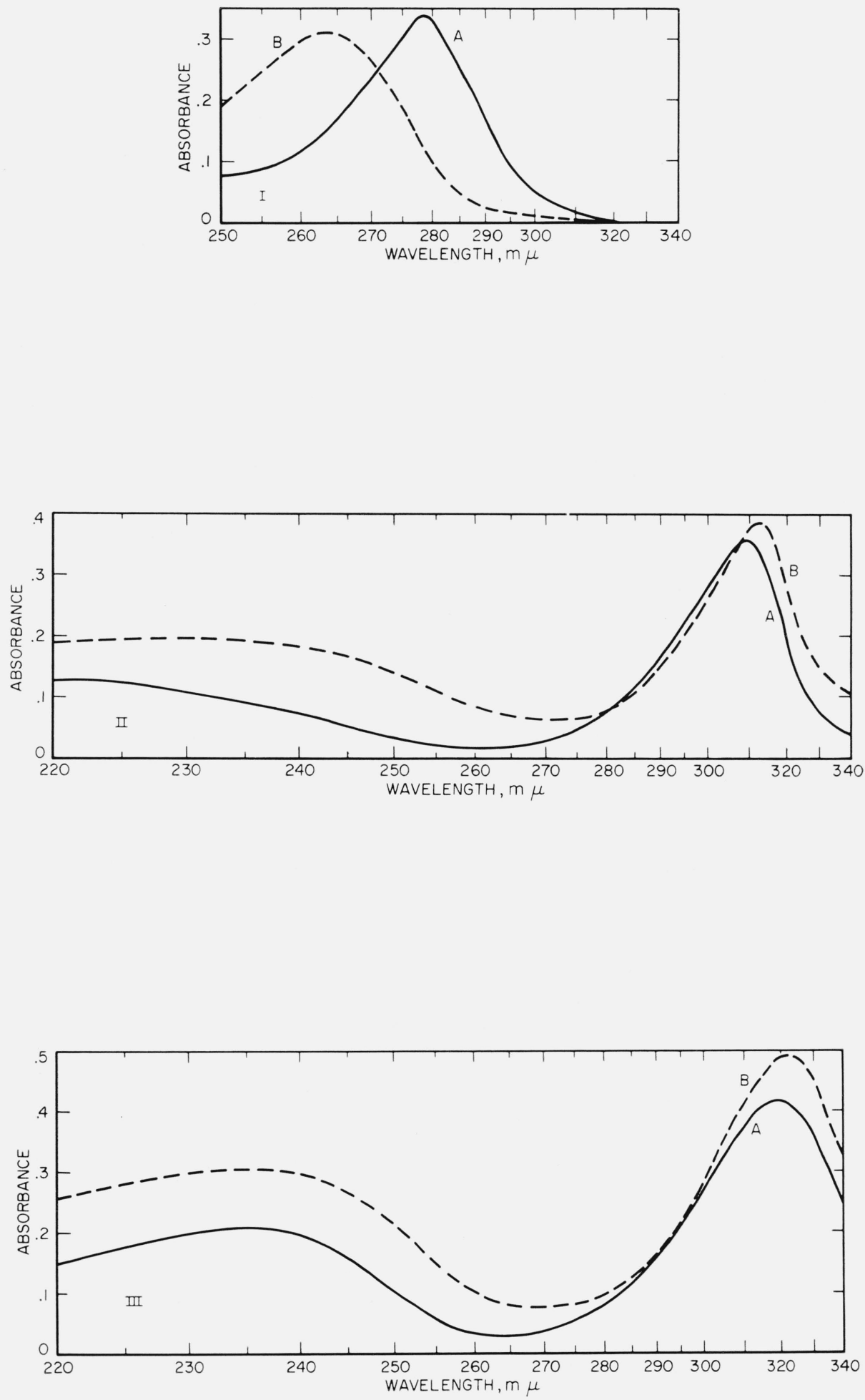

FiguRE 2. Ultraviolet spectrograms of materials.

I. Hexahydroxybenzene. Curve A, $7.39 \mathrm{mg}$ of $\mathrm{I}$ in $100 \mathrm{ml}$ of $6 \mathrm{~N} \mathrm{HCl}$ in methanol, $3 \mathrm{~min}$ after dissolution; $\lambda_{\max }$ at $278 \mathrm{~m} \mu$. Curve B, $67 \mathrm{mg}$ of the hexaacetate of I in $200 \mathrm{ml}$ of glacial acetic acid, $10 \mathrm{~min}$ after dissolution; $\lambda_{\max }$ at $263 \mathrm{~m} \mu$. II. Tetrahydroxyquinone. Curve A, $3.82 \mathrm{mg}$ of II in $1000 \mathrm{ml}$ of $2 \mathrm{~N}$ aqueous HCl, $24 \mathrm{hr}$ after dissolution; $\lambda_{\max }$ at 308 $\mathrm{m} \mu$. Curve B, $7 \mathrm{mg}$ of II in $1000 \mathrm{ml}$ of methanol, $30 \mathrm{~min}$ after dissolution; $\lambda_{\max }$ at $312 \mathrm{~m} \mu$.

III. Rhodizonic acid dihydrate. Curve A, $6.87 \mathrm{mg}$ of III in $1000 \mathrm{ml}$ of $2 N$ aqueous HCl $24 \mathrm{hr}$ after dissolution; $\lambda_{\max }$ at $235 \mathrm{~m} \mu$ and at $319 \mathrm{~m} \mu$. Curve B, $8.58 \mathrm{mg}$ of III in $1000 \mathrm{ml}$ of methanol, $5 \mathrm{~min}$ after dissolution; $\lambda_{\max }$ at $235 \mathrm{~m} \mu$ and at $323 \mathrm{~m} \mu$. In the visible region, III shows absorption at $443 \mathrm{~m} \mu$ and at $487 \mathrm{~m} \mu$ (sh). 

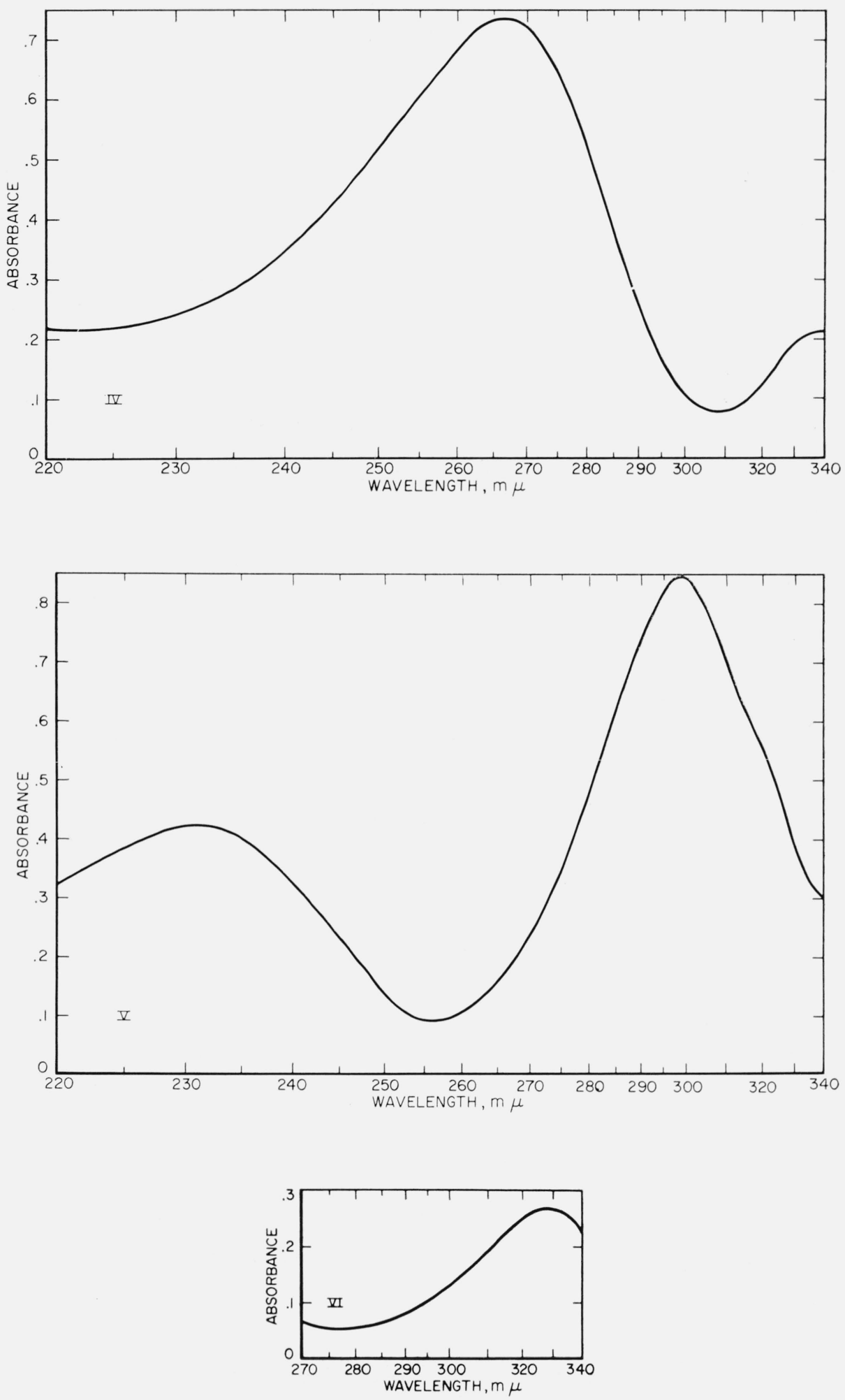

FiguRE 2. Ultraviolet spectrograms of materials - Continued.

IV. Triquinoyl octahydrate. $3.24 \mathrm{mg}$ of IV in $100 \mathrm{ml}$ of $2 N$ aqueous $\mathrm{NaCl} 1.5 \mathrm{hr}$ after dissolution; $\lambda_{\max }$ at $267 \mathrm{~m} \mu$. In the visible region, IV shows marked absorption at $363 \mathrm{~m} \mu, 440 \mathrm{~m} \mu(\mathrm{sh})$ and $480 \mathrm{~m} \mu$. $\mathrm{V}$. Croconic acid trihydrate. $5.87 \mathrm{mg}$ of $\mathrm{V}$ in $100 \mathrm{ml}$ of $2 N$ aqueous $\mathrm{HCl}, 10 \mathrm{~min}$ after dissolution; $\lambda_{\max }$ at $231 \mathrm{~m} \mu$ VI. Leuconic acid pentahydrate. $156.45 \mathrm{mg}$ of VI in $50 \mathrm{ml}$ of water, $5 \mathrm{~min}$ after dissolution; $\lambda_{\max }$ at $328 \mathrm{~m} \mu$.

161 


\section{References}

[1] T. Posternak, Helv. Chim. Acta 19, 1333 (1936); 1045 (1941).

[2] T. Posternak and J. Deshusses, Helv. Chim. Acta 44, 2089 (1961).

[3] N. Z. Stanacev and M. Kates, J. Org. Chem. 26, 912 (1961).

[4] H. S. Isbell, Ann. Rev. Biochem. 12, 213 (1943).

[5] H. S. Isbell, J. Research NBS 32, 45 (1944).

[6] R. West and Hsien-Ying Niu, J. Am. Chem. Soc. 84, 1324 (1962); Chem. Eng. News 40, 40 (1962).

[7] Beilsteins Handb. Org. Chemie 6, 1198, Springer, Berlin (1923).

[8] R. Nietzki and T. Benckiser, Ber. 18, 1833 (1885).

[9] A. J. Fatiadi (with W. F. Sager), M. S. Thesis, 1959, The George Washington University, Washington, D.C.

[10] R. Nietzki and T. Benckiser, Ber. 18, 499 (1885).

[11] P. W. Preisler and L. Berger, J. Am. Chem. Soc. 64, 67 (1942).

[12] R. C. Anderson and E. S. Wallis, J. Am. Chem. Soc. 70, 2931 (1948).

[13] A. J. Fatiadi and W. F. Sager, Org. Syntheses 42, (a)66, (b) 90 (1962).

[14] Louis F. Fieser and Mary Fieser, Advanced Organic Chemistry, f. 757 (Reinhold Publ. Corp., New York, N.Y., 1961).

[15] B. Homolka, Ber. 54, 1393 (1921).

[16] R. Robinson and C. Vasey, J. Chem. Soc. 1941, 660

[17] Beilsteins Handb. Org. Chemie 8, 534, Springer, Berlin (1925).

[18] H. J. Backer and S.v.d. Baan, Rec. Trav. Chim. 56, 1161 (1937).

[19] R. Kubn, G. Quadbeck, and E. Rohm, Ann. 565, 1 (1949).

[20] B. Eistert and G. Bock, Angew. Chem. ro, 595 (1958).

[21] Beilsteins Handb. Org. Chemie 8, 535, Springer, Berlin (1925).
[22] B. Eistert, G. Bock, E. Kosch, and F. Spalink, Chem. Ber. 93, 1451 (1960)

[23] Beilsteins Handb. Org. Chemie $\boldsymbol{g}, 907$, Springer, Berlin (1925).

[24] J. Lerch, Ann. 124, 34 (1862).

[25] R. Nietzki and F. Kehrman, Ber. 29, 322 (1887).

[26] F. Henle, Ann. 350, 330 (1906).

[27] F. Bergel, Ber. 62, 490 (1929).

[28] Beilsteins Handb. Org. Chemie 8, 489, Springer, Berlin (1925).

[29] L. Gmelin, Ann. Phys. 4, 31 (1825).

[30] J. Liebig, Ann. 11, 182 (1834).

[31] R. Nietzki and T. Benckiser, Ber. 19, 293 (1886).

[32] R. Nietzki, Ber. 20, 1617 (1887).

[33] R. Nietzki, Ber. 23, 3136 (1890).

[34] O. Gelormini and E. Artz, J. Am. Chem. Soc. 52, 2483 (1930).

[35] R. Malachowski and S. Prebendowski, Ber. \%1, 2241 (1938)

[36] Y. Hirata, K. Inukai, and T. Tsujiuchi, J. Chem. Soc. Japan 69, 63 (1948); C. A. 47, 5902 (1953).

[37] F. Arcamone, C. Prevost, and P. Souchay, Buil. Soc. Chim. France 1953, 891.

[38] S. Ruthkowski, Rocz. Chem. 36, 169 (1962).

[39] B. Carlquist and D. Dyrssen, Acta Chem. Scand. 16, 94 (1962).

[40] K. Yamada and Y. Hirata, Bull. Chem. Soc. Japan 31, 550 (1958)

[41] M. Harfenist, A. Barley, and W. A. Lazier, J. Org. Chem. 19, 1608 (1954).

[42] Beilsteins Handb. Org. Chemie $\boldsymbol{7}$, 905, Springer, Berlin (1925).

[43] H. Will, Ann. 118, 177 (1861).

[44] B. Homolka, Ber. 55, 1310 (1922).

(Paper 67A2-202) 